\title{
Comparative Citation Analysis of Applied Linguistics ResearCH Articles' InTRODUCTION SECTIONS
}

\begin{abstract}
Citation, as a rhetorical feature, is "central to the social context of persuasion" and plays a significant role in establishing knowledge (Hyland 1999: 341). Having knowledge about citation practice is necessary for the academics to make a good relationship between academic writers and previous researchers in the special fields. The purpose of this study was to compare citation practices in the introduction sections of applied linguistics research articles. To this end, 168 research article introduction sections were randomly selected from international and local Iranian research articles published in English in the field of applied linguistics. The data were then analyzed based on Thompson and Tribble's (2001) taxonomy of citation practices. Findings showed that local Iranian research articles tended to use more citation practice than international research articles. Results of descriptive and inferential statistics were also reported and their pedagogical implications were subsequently discussed.
\end{abstract}

\section{Keywords}

Applied linguistics; citation practice; integral citation; introduction sections; non-integral citation; research articles

\section{Introduction}

Research articles, as a common academic genre, are the path through which researchers report their findings. In this connection, introduction sections are one of the most important parts of a research article because this is the first section containing the knowledge pertaining to the arguments and importance of the study. 
Indeed, the function of this section is to help readers understand the arguments by providing ample information (Belcher 2009). According to Swales and Feak (2012), two functions of the introduction sections are to first, provide justification for the article and second, to motivate readers to read the article. Therefore, the author's skill in developing the concept appropriately to impress and convince the readership to read the article is very crucial. In the same vein, what makes an academic writing different from other types of genres is the formality level of a text which is quite challenging (Hyland 2006).

Academic writers and especially nonnative writers are expected to be cognizant of the ethics of appropriate citation practice to prevent plagiarism. However, lack of adequate knowledge on citation practices has proved problematic for nonnative academic writers (Paltridge 2002). According to Thompson (2001), it is possible to develop writing among other skills by increasing the audience's awareness and ability through written texts which, in effect, act as the dialogue between the writer and reader. The written text will display the ability of the writer to exchange a piece of information. The writer should be able to respond to the questions arising from reading the text (Thompson 2001).

Swales $(1986,1990)$ introduced two types of integral and non-integral citation forms. Whereas integral citation practices refer to a strategy in the use of citation practice that is put within the sentence and has a grammatical role in the sentence, non-integral citation practices do not have any grammatical role in the sentence and are put in a bracket. Integral citation is further divided into three subcategories of verb controlling, naming and non-citation. Non-integral citations are also divided into three subcategories of source, identification, reference and origin (Thompson and Tribble 2001).

Since citation practice varies across cultures and disciplines (Hayland 1999; Jalilifar 2012; Jalilifar and Dabbi 2012), research on this topic can provide invaluable knowledge for researchers in general and novice writers in particular. Therefore, this study sought to compare the rhetorical function of citation practice in introduction sections of applied linguistics research articles published in international as well as Iranian local journals. According to Kamyabi, Ghonsooly and Mahdavi (2014), in spite of the importance of citation in the academic writing, there seems to be a paucity of research evidence as to citation practice in academic courses. Moreover, in most English for Specific Purposes textbooks, the importance is chiefly attached to surface manifestations of citation, i.e., quotation, summary, and prophases (Thompson and Tribble 2001).

Citation, as a rhetorical feature, is "central to the social context of persuasion" and plays a significant role in establishing knowledge (Hyland 1999: 341). Having knowledge about citation practice is necessary for the academics to make a good relationship between academic writers and previous researchers in the special fields. The study of citation practices has increasingly occupied researchers' attention in the last two decades (Hryniuk 2016). For instance, a great number of studies addressed citation practices in MA theses (e.g. Nguyen and Pramoolsook 2016; Samraj 2013), PhD theses (e.g. P. Thompson 2001; Thompson and 
Tribble 2001; Soler-Monreal and Gil-Salom 2011; Zainuddin and Shaari 2017), research proposals (e.g. Fazel and Shi 2015) or research articles (e.g. CarterThomas and Rowley-Jolivet 2013; Charles 2006; Hewings, Lillis and Vladimirou 2009; Hryniuk 2016; Hua and Wang 2014; Lillis et al. 2010) or self-referencing (Mur-Dueñas and Šinkūnienė 2016) cross-culturally and in various disciplines. Many studies have also investigated citation practices in Iranian academic writings cross-culturally or/and in diverse disciplines (e.g. Kamyabi, Ghonsooly and Mahdavi 2014; Karimi and Asadnia 2014; Jalilifar and Dabbi 2012; Shooshtari and Jalilifar 2010; Shooshtari, Jalilifar and Shahri 2017).

Jalilifar and Dabbi (2012) investigated citation practice used in the introduction sections of Iranian master's theses in the field of applied linguistics using Thompson and Tribble's (2001) framework. The results of the study revealed significant differences between the number of integral citations and non-integral citations used by Iranian theses writers. It was observed that MA students tended to use integral citation practice in their theses. To provide a plausible explanation for the findings, Jalilifar and Dabbi noted that MA students had different views about the definition of citation practice so they used different kinds of citation practice in their theses. The use of various types of citation practice caused some difficulties for novice writers' appropriate citation practice. In a contrastive study, Soler-Monreal and Gil-Salom (2011) examined the interactional resources of citation in the review literature sections of $\mathrm{PhD}$ theses. The corpus consisted of $20 \mathrm{PhD}$ theses in the subfield of computation and computer engineering. The theses were written by native speakers of English and Spanish during the last decade. The data were analyzed based on Swales' (1990) classification of citation and Thompson and Ye (1991) and Hyland's $(1999,2002)$ taxonomy of reporting verbs. The findings showed that the English writers tended to use the integral citations while Spanish writers showed a preference to use non-integral citations. Put another way, Spanish writers used their own words, so they somewhat marginalized the significance of the author's role. With regard to the use of reporting verbs, the results showed that English theses showed more variation and higher occurrence of reporting verbs compared to Spanish corpus. Soler-Monreal and Gil-Salom (2011) state that the use of appropriate citation practice will create a guarantee for what an academic writer claims to judge about and the effective use of citation practice provides optimum conditions for establishing a connection with the members of a discourse community. Besides, Soler-Monreal and Gil-Salom (2011) emphasized that academic writers must recognize the value of contributions the authorities have made previously. Therefore, citing and referring to previous studies can be considered as a politeness strategy to accept other authors' views and highlight their achievements.

In another cross-linguistic study, Kamyabi, Ghonsooli and Mahdavi (2014) examined the use of integral and non-integral citation practices. To this end, they analyzed 60 research articles published in Iranian and international Scopus-indexed journals based on Thompson and Tribble' (2001) framework of citation analyses. Their findings revealed that the number of citations used in international Scopus 
journals was greater than that of citations used in the Iranian corpus. In addition, citations were used more frequently in the introduction sections and less frequently in the abstract sections of research articles. Elsewhere, Karimi and Asadnia (2014) examined the citation practice in the discussion sections of applied linguistics research articles published in international and Iranian local journals. They reported that Iranian local articles used more non-integral citation patterns.

In a more recent study, Shooshtari, Jalilifar and Shahri (2017) investigated the use of citation in English and Persian hard and soft science research articles. To this end, they analyzed 240 research articles using Coffin's (2009) integrative analytic framework. Their findings showed variations in the use of citation in their corpora; yet these researchers did not find significant differences among disciplines (i.e. applied linguistics, psychology, computer engineering and mechanical engineering) and languages (i.e. English and Persian).

The previous studies on cross-linguistic and cross-disciplinary differences on citation have provided great insight into our understanding of citation practices in different cultures and languages. Given the importance of citation in academic writing and also its cross-cultural variability, this research aimed to explore how citations are used in introduction sections of international and local Iranian research articles in the field of applied linguistics. The study, therefore, aimed to examine the rhetorical functions of citation practice in the introduction sections of applied linguistics research articles published in international and local Iranian journals. The following objectives guided the study:

1. To examine the types of rhetorical functions of citation used in the research article introduction sections of international and local Iranian journals

2. To find out whether there are any statistically significant differences in terms of citation practices in international and local Iranian journals

\section{Methodology}

The corpus consisted of 168 introduction sections of the different research articles (80 International articles and 86 local Iranian articles) in the field of Applied Linguistics. The introduction sections were randomly selected from international articles and local Iranian articles published in the last decade in leading journals of applied linguistics.

As was pointed out earlier, the study aimed to examine the citation practices in introduction sections of applied linguistics research articles. Given the crosslinguistic nature of the study, the number of words in each corpus was kept equal. In other words, each corpus consisted of around 63527 words. The corpus was read sentence by sentence and the strategies were identified and coded based on Thompson and Trible's (2001) framework. To ensure the reliability of data analysis, two raters double-checked the codification of the data yielding an inter-rater reliability coefficient of 0.9 . 
According to Thompson and Tribble (2001), citation practices are divided into two major categories with some subcategories: Non-integral citation practices include source, identification, reference and origin strategies. Verb controlling, naming and non-citation strategies also belong to integral citation practices. The framework is presented in Table 1.

Table 1. Thompson and Tribble's (2001) framework

\begin{tabular}{|l|l|l|}
\hline Types & Subcategory & Definition \\
\hline \multirow{4}{*}{$\begin{array}{l}\text { Non-integral } \\
\text { Citation }\end{array}$} & Source & $\begin{array}{l}\text { It refers to place where information come } \\
\text { from. }\end{array}$ \\
\cline { 2 - 3 } & Identification & $\begin{array}{l}\text { This kind of non-citation practice is used to } \\
\text { identify agent in a sentence. }\end{array}$ \\
\cline { 2 - 3 } & Reference & $\begin{array}{l}\text { This type of non-citation acts as a signal to re- } \\
\text { fer to further information in other researches }\end{array}$ \\
\cline { 2 - 3 } & Origin & $\begin{array}{l}\text { This kind of citation focuses on the originator } \\
\text { of the method, the theory, the approach, etc. }\end{array}$ \\
\hline \multirow{3}{*}{$\begin{array}{l}\text { Integral } \\
\text { citation }\end{array}$} & Verb Controlling & A special verb will follow the cited statement. \\
\cline { 2 - 3 } & Naming & $\begin{array}{l}\text { The noun phrase or part of the noun phrase } \\
\text { will follow the cited statement. }\end{array}$ \\
\cline { 2 - 3 } & Non-Citation & $\begin{array}{l}\text { The statement will be cited without the year } \\
\text { of publication. It is used to avoid the repeated } \\
\text { thing for being used in earlier sentences. }\end{array}$ \\
\hline
\end{tabular}

To analyze the data, each article was read sentence by sentence and the elements of citation practices were identified and checked. The data were then entered into SPSS software version 22 for further descriptive (i.e. frequency) and inferential statistics (i.e. chi-square).

\section{Results}

The results are reported in terms of non-integral and integral citation practices.

\subsection{Non-integral citation practice}

In this form of citation, the author's name is out of the sentence and as such does not have any grammatical role in the cited statements. Results of analyses are presented in Table 2. The description of the table comes under the following headings. 
Table 2. The Percentage and Frequency of Non-integral citation Practice in Two Corpora

\begin{tabular}{|c|c|c|c|c|c|c|c|c|}
\hline \multirow[t]{2}{*}{ Strategy } & & \multicolumn{2}{|c|}{$\begin{array}{l}\text { International } \\
\text { Journals }\end{array}$} & \multicolumn{2}{|c|}{$\begin{array}{l}\text { Local Iranian } \\
\text { Journals }\end{array}$} & \multirow[t]{2}{*}{$\begin{array}{l}\text { Chi } \\
\text { Square }\end{array}$} & \multirow[t]{2}{*}{ Df } & \multirow[t]{2}{*}{$\begin{array}{l}\text { Asymp. } \\
\text { Sig. }\end{array}$} \\
\hline & & $\mathrm{F}$ & $\%$ & $\mathrm{~F}$ & $\%$ & & & \\
\hline \multirow{4}{*}{$\begin{array}{l}\text { Non } \\
\text { integral } \\
\text { citation }\end{array}$} & Source & 447 & 47.4 & 497 & 52.6 & 2.648 & 1 & .104 \\
\hline & $\begin{array}{l}\text { Identifica- } \\
\text { tion }\end{array}$ & 298 & 65.9 & 154 & 34.1 & 45.876 & 1 & $<.001$ \\
\hline & Reference & 45 & 80.4 & 11 & 19.6 & 20.643 & 1 & $<.001$ \\
\hline & Origin & 37 & 50.0 & 37 & 50.0 & .000 & 1 & 1.000 \\
\hline Total & & 827 & & 696 & & & 1 & $<.000$ \\
\hline
\end{tabular}

\subsubsection{Source}

Source refers to the place where a piece of information comes from. The writers use this strategy to report what they read and consider this citation practice as a place to show their reports.

As shown in Table 1, the number of source strategies used in local articles $(n=497)$ was greater than the number of source strategies used in international articles $(n=447)$. However, despite the difference, results of chi-square analyses displayed no statistically significant difference in the use of source in the two corpora (sig. $=0.104$, p-value $<0.05$ ). Examples extracted from the corpus and numbered in brackets are as follows:

Extracts from international journals

(1) Social media sites are used as a source of health information by over a third of adults in developed nations (Fox 2011) and facilitate the easy, low-cost production of multimodal health discourses by a range of lay individuals and institutional agents.

(2) Most of the studies in the field focus on statements of worry and concern, reassurance, empathy, legitimation, and positive regard by analyzing doctors' question formats and content, body language (Roter 2000), or the linguistic features used to display shared awareness of patients' problems and feelings, and openness and checking techniques (Norfolk et al. 2007).

Extracts from local Iranian journals

(3) A core theoretical assumption behind constructivism is the centrality of reader's purposes or goals in the learning situations (Cambourne 2002). 
(4) Knowledge of vocabulary plays a significant role in almost all domains of language pedagogy (Alavi and Akbarian 2008).

\subsubsection{Identification}

This kind of non-citation practice is used to identify the agent within the sentence it refers to (Thompson and Tribble, 2001). In other words, the writers use this subcategory to indicate the author's identity. As shown in Table 1, the number of identification elements used in international articles $(n=298)$ is greater than articles $(n=154)$. Results of chi-square analysis showed that there was a statistically significant difference in the use of identification strategy in the two corpora (sig. $=0.001, \mathrm{p}$-value $<0.05)$. Examples from the corpus are as follows:

Extracts from international journals

(5) In light of this, and building on ongoing linguistic research (e.g., Hunt and Koteyko 2015), this paper adopts a critical social semiotic approach to analyze multimodal health communication on Facebook.

(6) Addressee-orientation in questions has been attested in many related languages, including Standard Tibetan (Tournadre 2008), Sherpa (Schottelndreyer 1980) and Dzongkha (Driem 1998: 131-132).

Extracts from local Iranian journals

(7) Also, surveys regarding students' attitudes toward feedback in ESL context (e.g., Ferris 1995; Satio 1994) and EFL context (e.g., Diab 2005; Enginalar 1993) indicate that learners are concerned about accuracy, and to them, an effective feedback is the one in which teachers pay attention to linguistic errors.

(8) Scholars have emphasized the importance of enhancing CT skills and critical language awareness in foreign language classrooms (Tarvin and Al-Arishi 1991; Davidson 1994; Chamot 1995).

\subsubsection{Reference}

Reference acts as a signal to refer to further information in other studies. The words "see" and "cf" are actual signs to identify this kind of non-citation practice in the text. As shown in Table 1, reference was used more frequently in native speaker corpus $(n=45)$ than nonnative speaker corpus $(n=11)$. Results of statistical analyses showed a significant difference in the use of reference in the two corpora (sig. $=0.001$, $\mathrm{p}$-value $=<0.05$ ). Demonstrative examples from the corpus are as follows: 
Extracts from international journals

(8) As evidentially becomes a well-described grammatical phenomenon crosslinguistically, analysis has moved from typological exploration of the semantic and grammatical properties of evidential to investigations of how these forms are used by people in interaction (see Michael 2012 for reported speech, San Roque et al. 2015 for questions, and some sections of Aikhenavald 2004).

(9) Apart from the obvious theoretical importance of whether even a short stay can make a difference, the question has high practical importance, given that such short stays are becoming an increasingly common mode of study abroad for language students (see e.g., Allen 2010: 453) and for many language students, including in Australia, such short courses are the only way that they study abroad.

Extracts from local Iranian journals

(10) When we look at such ideas and suggestions, it is clear that these researchers may have considered the role of speech community but their statements are essentially anecdotal and not based on official statistics (see Sadeghi 2001).

(11) Further, the mere consideration of ideas on the part of ideas linguists (see Zomorrodian 2003), men of literature (see Shari' at 1986) and other experts (see Haddad Adel 2003) involved in word-formation and word-selection seems to be insufficient.

\subsubsection{Origin}

This kind of citation relates to citing the originator of a method, theory, approach, etc. As displayed in Table 1, the use of origin in the two corpora is virtually the same $(n=37)$. Extracts featuring this practice from the corpus are as follows:

Extracts from international journals

(12) The constructivist nature of learning highlights the need for teachers to draw on different teaching styles (Ladd and Rubby 1999).

(13) This has also been referred to in the literature on Tibetan as an 'origo shift' (Garrett 2001: 225) from speaker to addressee.

Extracts from local Iranian journals

(14) Hawkins merged two important approaches to definiteness, namely, Russel- 
lian uniqueness approach (Russell 1905) and familiarity approach (Kamp 1981).

(15) The inception of Multiple Intelligence Theory (Gardner 1983) motivated a number studies in second language acquisition research.

The overall findings showed that non-integral citation practices were used more significantly in international journal corpus.

\subsection{Integral citation practice}

Integral citation practices have a grammatical role in the sentences. Based on Thompson and Tribble's (2001) classification, integral citation practice includes three subcategories: Verb controlling, naming, and non-citation strategy. Summary of the findings are set out in Table 2 .

Table 2. The Percentage and Frequency of Integral Citation Practice in Two Corpora

\begin{tabular}{|c|l|c|c|c|c|c|c|c|}
\hline \multicolumn{2}{|c|}{ Strategy } & \multicolumn{2}{|c|}{$\begin{array}{c}\text { Interna- } \\
\text { tional } \\
\text { journals }\end{array}$} & $\begin{array}{c}\text { Non-native } \\
\text { English } \\
\text { Corpus }\end{array}$ & $\begin{array}{c}\text { Chi } \\
\text { Square }\end{array}$ & df & $\begin{array}{c}\text { Asymp. } \\
\text { Sig. }\end{array}$ \\
\cline { 3 - 8 } \multicolumn{2}{|c|}{} & $\mathrm{F}$ & $\%$ & $\mathrm{~F}$ & $\%$ & & & \\
\hline \multirow{2}{*}{$\begin{array}{c}\text { Integral } \\
\text { Citation } \\
\text { Practice }\end{array}$} & Verb controlling & 173 & 34.1 & 335 & 65.9 & 51.661 & 1 & $<.001$ \\
\cline { 2 - 9 } & Naming & 97 & 42.5 & 131 & 57.5 & 5.070 & 1 & $<.024$ \\
\hline Total & Non-citation & 8 & 36.4 & 14 & 63.6 & 1.636 & 1 & .201 \\
\hline
\end{tabular}

\subsubsection{Verb controlling}

In this strategy a particular verb follows the cited statement. The function of the citation is an agent to control the verbs, in their active or passive forms. Through this strategy, writers attempt to show the special performance of a particular author in the writing. As presented in Table 2, verb controlling was used more frequently in local articles $(n=335)$ than international articles $(n=171)$. Results of chi-square analyses displayed that there was a statistically significant difference in the use of verb controlling in the two corpora (sig. $=0.001$, p-value $=<0.005$ ). The following extracts from the corpus delineate the use of verb controlling:

Extracts from international journals

(16) In relation to language variety, Rowley-Jolivet and Carter-Thomas (2005) observes differences in you and I in conference presentations. NNS scientists appear to avoid such interactional features preferred by their NS peers. 
Therefore, it would seem that particular linguistic features such as pronouns must be understood in relation to the (genre specific) purposes and practices of the events in which they occur.

(17) Fisher and Adams (1994) explained that by exchanging greetings, the participants affirm that they are connected to each other through a relational bond - even if that bond only means that the participants are co-members of a particular culture. They further argue that when two people greet each other, both expect that an interaction will follow, at least for some time.

Extracts from local Iranian journals

(19) Moreover, Pennington (1992) asserted that a reflective orientation improves classroom processes and outcomes.

(20) Second, task-based pedagogy is capable of a wide range of interpretations; that is, any single task, Ellis (2003) states, has the potential to be performed in a number of ways, depending on how the participants orient to it.

\subsubsection{Naming}

In this type of citation, a noun phrase or a part of noun phrase controls the citation. The purpose is to underscore the importance of what authors did in their studies or what they found in their research. As shown in Table 2, naming was used more frequently in local articles $(n=131)$ than international articles $(n=97)$. Results of chi-square analyses showed that there was a statistically significant difference in the use of this citation strategy in the two corpora (sig. $=0.024$, pvalue $=<0.05$ ). Examples from the corpus are as follows:

Extracts from international journals

(21) Looking exclusively at lecture introductions, Thompson (1994) used Swales' (1990) rhetorical move analysis to describe their structure. She notes that lecturers appear to be aware of the need to set up a framework for the lecture discourse and provide a context for the new information to come" (p. 182); however, she points out that lecture introductions seem to lack a preferred rhetorical order and also vary in their move structure.

(22) One important exception to this relative neglect of reception is the long paper by Paul, Charney, and Kendall (2001) in which they trace the reception histories of papers in the rhetoric of science. 
Extracts from local Iranian journals

(23) As Pishghadam and Mirzaee (2008) maintain, the educational system of Iran is still in the modern era (cited in Pishghadam and Naji Meidani, 2012, p. 466).

(24) Similar to Mirzaei and Eslami's (2013) study, genre analysis and critical discourse analysis were used to analyze the structure of WI texts and the sociocultural values revealed by the choice of different moves and its linguistic realization.

\subsubsection{Non-citation}

Through this strategy, the writer does not use the date of publication about the special statement cited in the writing because it has been stated in the previous sentences. In this type of subcategory, there is reference to another researcher, yet the name is given with no indication of the year of publication.

As shown in Table 2, non-citation strategy was used more frequently in local articles $(n=14)$ than international articles $(n=8)$. Results of statistical analyses, however, showed that there was not any significant difference in the use of noncitation strategy in the two corpora (sig. $=0.201$, p-value $=<0.05$ ). Examples from the corpus are as follows:

Extracts from international journals

(25) Vokurkova used quite large objects (such as buckets and bike helmets), but for portability I used smaller domestic items: glasses, a hat, a book, a packet of noodles and an onion or lemon.

(26) We owe an enormous debt in pragmatics to the work of a sociologist, Erving Goffman.

Extracts from local Iranian journals

(27) What Sadeghi means by "specialists outside the Academy" is not clear.

(28) The first author, Motaghi-Tabari, has been residing in Australia for several years, but originally comes from Iran, where complimenting is a common speech act in people's daily interactions.

\section{Discussion}

Citation has been considered as a technique by means of which academics cite their findings. The appropriate citation practice is a powerful tool at the author's 
disposal to influence the readers such that academics' lack of sufficient knowledge governing correct citation practice would likely lead to their inability to convey their purposes effectively. In addition, an understanding of citation is essential for academic writing as it enables authors to establish and maintain a good communication with readers through special texts.

The findings of the present investigation showed that both strategies of nonintegral and integral citations were present in the two corpora. Results displayed that identification and source were used more frequently in international articles than Iranian articles. In other words, they were used more significantly in international articles. The overall findings demonstrated the statistically significant difference in the use of non-integral citation in international and local articles in the introduction sections of research articles in the field of applied linguistics. The findings also displayed that local Iranian articles used verb controlling, naming and non-citation more frequently than international articles. Put differently, statistical analyses corroborated that integral citation strategies were used significantly more frequently in local Iranian articles.

These findings are in line with a number of previous studies (e.g. Kamyabi, Ghonsooly and Mahdav 2014; Karimi and Asadnia 2014; Shooshtari and Jalilifar 2010; Shooshtari, Jalilfar and Shahri 2017) where the number of non-integral citation practices in international journals was found to be greater than that of local Iranian journals.

The findings of this study are also consistent with those of Soler-Monreal and Gil-Salmon (2011) who reported that English writers used non-integral citations more frequently than local Spanish writers. According to Soler-Monreal and GilSalmon (2011: 72), the use of non-integral citation strategies displayed a tendency to "duplicate the author's original wording and make authors prominent through integral active verb-controlling forms". In other words, using non-integral citation strategies emphasizes personal commitment while the use of integral citation strategies reduces the implication of human intervention (Soler-Monreal and Gil-Salmon 2011).

These findings also chime with Kamyabi, Ghonsooly and Mahdavi's (2014) outcomes according to which Iranian local journals used integral citation strategies more frequently than international journals. In other words, Iranian writers "emphasized the writers than information" (Kampyabi, Ghonsooly and Mahdvai 2014: 155).

The findings of the present study also replicated Jalilifar and Dabbi's (2012) study in which Iranian MA students showed a tendency to use integral citation strategies significantly more frequently than non-integral citations. According to Jalilifar and Dabbi (2012), context is a determining factor in how a text should be written. Therefore, having the attitude and expectation of the readers in mind, the Iranian writers develop their texts accordingly.

Variation in the use of integral and non-integral citation depends on a number of factors such as "convention, genre, discipline and individual study type" (Thompson and Tribble, 2001: 317). However, as put by Kamyabi, Ghonsooly 
and Mahdavi (2014), this variation could also be due to the functions of citations in journals, when writers prefer to emphasize the author especially in subject position. In other words, the purpose is to express their claim strongly through emphasizing the authors rather than information (Kamyabi, Ghonsooly and Mahdavi 2014: 164/165).

The difference in giving citations between international journals and local Iranian journals may be due to:

"the strict denial of the [Iranian] writers' transparent visibility in academic texts at post-graduate level studies, lack of explicit instruction or adequate consciousness-raising on the importance of academic writer-reader relations, specific attention to the national audience that follow the standards set by Iranian journals' reviewers and gatekeepers.....and the inevitable dominance of certain sociocultural orientations operationalize by academic writers in the context of Iran". (Karimi and Asadnia 2014: 67)

So it seems that Iranian writers have been influenced by the culture when developing their research articles. It is difficult to draw a borderline between language and culture and while some language issues are considered a good style in one academic culture, they "create ambiguity or unwanted emphasis" in a language like English (Carter-Thomas and Rowley-Jolivet 2013: 22).

\section{Conclusion}

Learning different styles of citing and applying correct references in academic texts can affect the quality of a text. Among other features in academic writing, citations represent an "author's estimation of previous work in their field, help to construct the author as a member of his or her disciplinary community, and provide an opportunity to promote his or her own work, or the work of colleagues" (Hewings, Lillis and Vladimirou 2010: 102). Citation as one of the significant features in academic writing helps writers to "adopt a tone of authority and provide justification, validity and credibility for the arguments he or she proposed" (Shooshtar, Jalilifar and Shahri 2017:72). The results of this study displayed that international journals used non-integral citations significantly more frequently than local Iranian journals, while local Iranian journals used integral citations more significantly than international journals. In other words, as stated by Shooshtari, Jalilifar and Shahri (2017: 72), the Iranians' preference on use of integral citations over the non-integral citations indicated that "Persian [Iranian] culture seems to be more people oriented than performance oriented".

The findings of this study bear some pedagogical implications for teaching citations: First, novice scholars and EFL students should become familiar with the differences of citation application in international and local journals. Citation should be taught and learned with special consideration given to students' discipline, 
language and cultural contexts. Second, teachers should be responsible for providing occasions to practice these structures consciously and increase their students' awareness to use suitable structures to cite. In this regard, Thompson and Tribble (2001) suggest that teachers familiarize students with citation categories, give them a text to analyze in group, let them review their own citation practices, and finally give them a check-list to evaluate.

\section{Acknowledgement}

The authors would like to express their gratitude to the two anonymous reviewers for their constructive comments on an earlier draft of this manuscript.

\section{References}

Belcher, Wendy Laura (2009) Writing Your Journal Article in Twelve Weeks: A Guide to Academic Publishing Success. California: SAGE Publication.

Carter-Thomas, Shirley and Elizabeth Rowley-Jolivet (2013) Citation from a cross-linguistic perspective: the case of French researchers publishing in English. ESP Across Cultures 10, 111-126.

Charles, Maggie (2006) Phraseological patterns in reporting clauses used in citation: A corpusbased study of theses in two disciplines. English for Specific Purposes 25(3), 310-331. https:// doi.org/10.1016/j.esp.2005.05.003.

Coffin, Caroline Jane (2009) Incorporating and evaluating voices in a film studies thesis. Writing and Pedagogy 1(2), 163-193.

Fazel, Ismaeil and Ling Shi (2015) Citation behaviors of graduate students in grant proposal writing. Journal of English for Academic Purposes 20, 203-214. https://doi.org/10.1016/j. jeap.2015.10.002.

Hamp-lyons, Liz and Zhang Wenxia (2001) World Englishes: Issues in and from academic writing assessment. In Flowerdew, John and Matthew Peacock (eds.) Research Perspectives on English for Academic Purposes. Cambridge: Cambridge University Press, 101-116.

Hanania, Edith A.S. and Karima Akhtar (1985) Verb form and rhetorical function in science writing: A study of MS theses in biology, chemistry and physics. ESP Journal 4(1), 49-58. https:// doi.org/10.1016/0272-2380(85)90006-X

Hewings, Ann, Theresa Lillis and Dimitra Vladimirou (2010) Who's citing whose writings? A corpus based study of citations as interpersonal resource in English medium national and English medium international journals. Journal of English for Academic Purposes 9(2), 102-115. https:// doi.org/10.1016/j.jeap.2010.02.005

Hryniuk, Katarzyna (2016) The use of citations in research articles written by Polish and English native-speaker writers. In: Chodkiewicz Halina, Piotr Steinbrich and Malgorzata Krzemińska-Adamek (eds.) Working with Text and Around Text in Foreign Language Environments. Second Language Learning and Teaching. Cham: Springer, 143-157. https://doi.org/10.1007/978-3319-33272-7_9

Hua, Guangwei and Guihua Wang (2014) Disciplinary and ethnolinguistic influences on citation in research articles. Journal of English for Academic Purposes 14, 14-28. https://doi.org/10.1016/j. jeap.2013.11.001.

Hyland, Ken (1999) Academic attribution: Citation and the construction of disciplinary knowledge. Applied Linguistics 20(3), 341-367. https://doi.org/10.1093/applin/20.3.341 
Hyland, Ken (2002) Directives: Argument and Engagement in Academic Writing. Applied Linguistics, 23(2), 215-239. https://doi.org/10.1093/applin/23.2.215

Hyland, Ken (2004) Disciplinary interactions: Meta-discourse in L2 postgraduate writing. Journal of Second Language Writing 13(2), 133-151. https://doi.org/10.1016/j.jslw.2004.02.001

Hyland, Ken (2006) English for Academic Purposes: An Advanced Resource Book. London: Routledge.

Jalilifar, Alierza (2012) Academic attribution: Citation analysis in master's theses and research articles in applied linguistics. International Journal of Applied Linguistics 22(1), 23-41. https:// doi.org/10.1111/j.1473-4192.2011.00291.x

Jalilifar, Alireza and Razieh Dabbi (2012) Citation in applied linguistics: Analysis of introduction sections of Iranian master's theses. Linguistic online 7(12), 91-104. https://doi.org/10.13092/ 10.57.252

Kamyabi Gol, Atiyeh, Behzad Ghonsooly Hezareh and Esmaeil Mahdavi Soghondikolaei (2014) A contrastive study of rhetorical functions of citation in Iranian and international ELT Scopus journals. Linguistics and Literature Studies (6)2, 155-164. https://doi.org/10.13189/1ls.2014.020601.

Karimi, Mohammad Nabi and Fatemeh Asadnia (2014) Meta-discourse strategies and citation patterns as resources of authorial identity in research articles across international/local journals and applied linguistics sub-disciplines. The Journal of Teaching Language Skills 6(1), 49-72.

Lillis, Theresa, Ann Hewings, Dimitra Vladimirou and Mary Jane Curry (2010) The geolinguistics of English as an academic lingua franca: citation practices across English-medium national and English-medium international journals. International Journal of Applied Linguistics 20(1), 111-135. https://doi.org/10.1111/j.1473-4192.2009.00233.x

Malcolm, Lois (1987) What rules govern tense usage in scientific articles? English for Specific Purposes 6(1), 31-43. https://doi.org/10.1016/0889-4906(87)90073-1

Mur-Dueñas, Pilar and Jolanta Šinkūnienè (2016) Self-reference in research articles across Europe and Asia: a review of studies. Brno Studies in English 42(1), 71-92, https://doi.org/10.5817/ BSE2016-1-4.

Nguyen, Thi Thuy Loan and Issra Pramoolsook (2016) Citations in literature review chapters of TESOL master's theses by Vietnamese postgraduates. GEMA Online Journal of Language Studies $16(2), 17-32$.

Paltridge, Brian (2002) Theses and dissertation writing: An examination of published advice and actual practice. English for Specific Purposes 21(2), 125-143. https://doi.org/10.1016/S08894906(00)00025-9

Samraj, Betty (2013) Form and function of citations in discussion sections of master's theses and research articles. Journal of English for Academic Purposes 12(4), 299-310. https://doi. org/10.1016/j.jeap.2013.09.001

Shaw, Philip (1992) Reasons for the correlation of voice, tense and sentence function in reporting verbs. Applied Linguistics 13(3), 302-319. https://doi.org/10.1093/applin/13.3.302

Shooshtari Gooniband, Zohreh and Alireza Jalilifar (2010) Citation and the construction of disciplinary knowledge. Journal of Teaching Language Skills 2(1), 45-66.

Shooshtari Gooniband, Zohreh, Jalilifar, Alireza and Somayeh Shahri (2017) Ethnolinguistic Influence on citation in English and Persian hard and soft science research articles. 3L: The Southeast Asian Journal of English Language Studies 23(2), 58-74. https://doi. org/10.17576/3L-2017-2302-05

Soler-Monreal, Carmen and Luz Gil-Salom (2011) A cross-language study on citation practice in $\mathrm{PhD}$ theses. International Journal of English Studies 11(2), 53-75.

Swales, John M. (1986) Citation analysis and discourse analysis. Applied Linguistics 7(1), 39-56. https://doi.org/10.1093/applin/7.1.39

Swales, John M. (1990) Genre Analysis: English in Academic and Research Settings. Cambridge: Cambridge University Press. 
Swales, John M. and Christine B. Feak (2012) Academic Writing for Graduate Students, $3^{\text {rd }}$ ed. Michigan: The University of Michigan Press.

Thompson, Geoff (2001) Interaction in academic writing: Learning to argue with the reader. Applied Linguistics 22(1), 58-78. https://doi.org/10.1093/applin/22.1.58

Thompson, Geoff and Yiyun Ye (1991) Evaluation in the reporting verbs used in academic papers. Applied Linguistics 12(4), 365-382. https://doi.org/10.1093/applin/12.4.365

Thompson, Paul (2001) A pedagogically-motivated corpus-based examination of PhD theses: macrostructure, citation practices and uses of modal verbs. Thesis dissertation, School of Linguistics and Applied Language Studies, University of Reading.

Thompson, Paul and Chris Tribble (2001) Looking at citations: Using corpora in English for Academic Purposes. Language Learning and Technology (5)3, 91-105.

Zainuddin, Siti Zaidah and Azianura Hani Shaari (2017) Contextual layers in the establishment of research niche in doctoral thesis introductions by Malaysian writers. GEMA Online ${ }^{\circledR}$ Journal of Language Studies 17(2), 146-162.

Maryam Farnia is Assistant Professor of Applied Linguistics at the Department of Linguistics and Foreign Languages, Payame Noor University, Iran. Her areas of research include genre analysis, interlanguage pragmatics, humor, im/politeness and speech act. She can be reached through mfarniair@gmail.com.

ZoHReH BAGHERI received her MA in English Language Teaching from Payame Noor University, Iran. She has been teaching English at foreign language institutes since 2015. She has presented papers at national and international conferences. Her areas of research are discourse analysis and language teaching. She can be reached through zohrebagheri1358@gmail.com.

Masoud SAeEdi is Assistant Professor of TEFL at the Department of Linguistics and Foreign Languages of Payame Noor University, Iran, where he currently teaches graduate and undergraduate courses including second language assessment, second language pedagogy, and teaching second language skills. His academic efforts and output have been mainly focused on task design and implementation variables, second language speech production, dimensions of L2 production, namely complexity, accuracy, fluency, and L2 learners' self-correction behaviour. He can be reached through saeedi.tefl@gmail.com.

Address: Department of Foreign Languages and Linguistics, Payame Noor University, PO BOX: 19395-3697, Tehran, Iran. 